\title{
Do personality traits have an impact on anxiety levels of athletes during the COVID-19 pandemic?
}

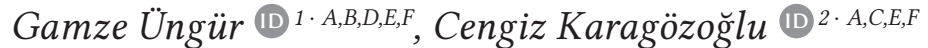 \\ 1: Faculty of Sport Sciences, Dokuz Eylül University, Izmir, Turkey \\ 2: Faculty of Sport Sciences, Marmara University, Istanbul, Turkey
}

\section{BACKGROUND}

The sports world is one of the sectors most affected by the SARS-CoV-2 (COVID-19) pandemic. Athletes from specific sport disciplines have experienced the new situation in different ways. Therefore, understanding their individual experiences and psychological responses may help to design better intervention programs. Accordingly, this study investigated the relationship between athletes' personality traits and anxiety in the light of their individual experiences during the COVID-19 pandemic.

PARTICIPANTS AND PROCEDURE

The COVID-19 impact questionnaire, Big Five Inventory-35, and the State-Trait Anxiety Inventory were administered to 321 male and 168 female athletes in Turkey from various sport disciplines. At the time of data collection, training and competitions had been canceled in all sports for two months.

\section{RESULTS}

Most athletes (70.7\%) were worried about being infected with SARS-CoV-2 if competitions were to restart soon
The regression analyses revealed that emotional stability, extroversion, and age were negative predictors of state anxiety; emotional stability, extroversion, and conscientiousness were negative predictors of trait anxiety; agreeableness was a positive predictor of state anxiety. Athletes who perceived that their relationships with family or close friends worsened during home confinement (17.2\%) had significantly higher state anxiety and trait anxiety scores than those who perceived a positive relationship change $(28 \%)$ or no relationship change (54.8\%). The agreeableness, conscientiousness, and emotional stability scores of athletes who perceived a negative relationship change with family or close friends were also significantly lower than for athletes who perceived no change or a positive change.

CONCLUSIONS

Overall, personality traits affected athletes' anxiety levels and their relationships during the COVID-19 pandemic.

KEY WORDS

sport; trait anxiety; coronavirus; state anxiety; Big Five personality traits

CORRESPonding AUthor - Gamze Üngür, Ph.D., Faculty of Sport Sciences, Dokuz Eylül University, Izmir Road,

Çolak Ibrahim Bey District 91/3, 35460 Seferihisar, Izmir, Turkey, e-mail: gamze.ungur@deu.edu.tr

AUTHORS' CONTRIBUTION - A: Study design - B: Data collection · C: Statistical analysis - D: Data interpretation

E: Manuscript preparation · F: Literature search · G: Funds collection

TO CITE THIS ARTICLE - Üngür, G., \& Karagözoğlu, C. (2021). Do personality traits have an impact on anxiety levels

of athletes during the COVID-19 pandemic? Current Issues in Personality Psychology, 9(3), 246-257.

RECEIVED 31.01.2021 · REVIEWED 19.03.2021 · ACCEPTED 01.04.2021 · PUBLISHED 15.05.2021 


\section{BACKGROUND}

The rapid global spread of SARS-CoV-2 since it was first identified in China's Hubei province on 31 December 2019 has infected millions of people and caused hundreds of thousands of deaths. These rapid developments triggered a shock wave that has been called "a global trauma” (Aşkın et al., 2020) resulting in psychological and mental disorders worldwide (Salari et al., 2020). After sport events were cancelled or postponed and sports centers had to close their doors (Blocken et al., 2020), most professional sports were put on hold (Carmody et al., 2020), with most athletes isolating themselves in compliance with social distancing measures taken in response to the COVID-19 pandemic. Although athletes are younger and have fewer comorbidities than the general population (Toresdahl \& Asif, 2020), research findings and expert reports revealed that the COVID-19 pandemic had a significant impact on their physical and mental state (Jukic et al., 2020), causing mental health burdens and risks (Claussen \& Scherr, 2020), worsened physical and psychological qualities (Stokes et al., 2020), uncertainty about returning to sports and depression (Pillay et al., 2020), poorer mental health, burnout syndrome, alienation, and poor coping responses (Schinke et al., 2020), greater risks of skeletal muscle, tendon, and cartilage changes for team sports practitioners (Paoli \& Musumeci, 2020), and some COVID-19 cases (Tekkurşun Demir et al., 2020; Corsini et al., 2020). After the Tokyo 2020 Olympics were postponed, Taku and Arai (2020) found both positive and negative effects on athletes and coaches, with some athletes retiring from competitive sports while others considered it an opportunity to gain better form or recover from injuries.

Due to the nature of the COVID-19 pandemic, psychological studies follow a slower pace than medical research. The sports world has gradually started to reopen training areas and major leagues in some sports, such as football, basketball, handball, winter sports, wrestling, and judo. However, restarting sports activities after a long break due to the pandemic creates physical and psychological risks while the manner of restarting sports activities is still under debate. In football, a few countries terminated their 2019-2020 league seasons (e.g. France and the Netherlands) whereas most federations, led by Germany, restarted their leagues, such as Italy, England, and Turkey. Mann et al. (2020) have asked "what a return to sport will look like after this pandemic". After the initial shock, by the end of 2020 , many sports had restored their competition schedules in line with "the new normal conditions". Given these rapid developments, scientists need to understand athletes' conditions as soon as possible, with one of the most important areas being psychological studies.
Numerous studies have investigated the relationship between personality traits and other psychological factors, such as anxiety, depression, and coping strategies. For example, anxiety and depression are generally considered to be correlated with personality traits (De Moor et al., 2006). Bolger and Eckenrode (1991) found that extraversion and neuroticism personality traits play an important role in major stressful events in relation to social support. Leandro and Castillo (2010) reported that neuroticism has different effects on coping strategies in men and women.

Regarding the COVID-19 pandemic specifically, Brouard et al. (2020) found that personality traits predict compliance with COVID-19 measures. Bacon and Corr (2020) concluded that "defensive personality traits are involved in concerns about the coronavirus", while Carvalho et al. (2020) found that people with high extroversion scores experienced greater difficulty during the pandemic. Garbe et al. (2020) found that HEXACO personality traits influence redundant behavior during the pandemic. Specifically, people with high conscientiousness were more likely to stockpile toilet paper. Thus, understanding how different personality traits affect coping behavior during the pandemic can help in creating intervention programs based on individual needs.

The sports and exercise psychology literature has examined extroversion, openness, and agreeableness traits, although neuroticism (e.g. anxiety and depression) and conscientiousness (e.g. self-efficacy and competitiveness) traits are more frequently represented in terms of their associated characteristics (Laborde et al., 2019). Not all athletes can be expected to cope alike with the stress and anxiety caused by the COVID-19 pandemic. While a certain level of anxiety during this period is acceptable, high anxiety levels can affect life negatively (Pakpour \& Griffiths, 2020). Given that athletes' individual characteristics, especially personality traits, may influence levels of anxiety during this period, understanding their individual experiences and psychological responses may help to design better intervention programs.

Accordingly, this study had two aims: firstly, to investigate the impact of personality traits on athletes' anxiety levels during the COVID-19 pandemic; secondly, to examine possible relationships between personality traits and athletes' individual experiences of the pandemic, particularly the major stressor of postponing or cancelling sports competitions.

\section{PARTICIPANTS AND PROCEDURE}

\section{PARTICIPANTS}

Due to the conditions of the lockdown period, the research sample was determined using convenience sampling. The 489 participants (321 men, 168 women) 
included individual and team athletes contacted through their coaches, accessed via the internet, at various national sports clubs. Participation was voluntary. Among the participants, 245 athletes reported that they compete at a professional level and 244 athletes at an amateur level in their specific sports disciplines. Mean age was $21.28(S D=5.42)$ and average competitive experience in years was $9.07(S D=5.31)$. The main sports represented were football (195 participants), volleyball (70), basketball (26), athletics (39), martial arts (70), shooting (27), with 62 from other disciplines (handball, gymnastics, swimming, underwater rugby, weightlifting, fencing, horse riding, bocce, orienteering, modern dancing, windsurf, kitesurfing, and curling). Regarding level, 115 (23.5\%) athletes were from their sport's highest league, 54 (11.0\%) from the second league, $20(4.1 \%)$ from the third league, $10(2.0 \%)$ from the fourth league, $235(48.1 \%)$ from lower leagues, and $55(11.2 \%)$ without a league.

\section{PROCEDURE}

At the time of data collection, the athletes had been under home confinement for two months (depending on their city), in line with government decisions supported by Turkey's National Scientific Advisory Board for the COVID-19 pandemic. All training and sports competitions had been canceled, alongside general national restrictions to keep individuals at home. Consequently, 341 athletes $(74.3 \%)$ had done no field training with their coaches within the previous month. Data were collected using a COVID-19 impact questionnaire, the Big Five Inventory-35, and the State-Trait Anxiety Inventory (STAI). Data collection was announced to athletes by their coaches, and all questionnaires were administered via Google Forms between May 28, 2020 and June 1, 2020 in compliance with social distancing rules.

\section{MEASURES}

Big Five Inventory-35 (BFI-35). The Big Five Inventory-35, developed by Goldberg (1992) and adapted for Turkish samples by Tatar et al. (2019), asks participants to rate themselves in relation to 35 bipolar adjective pairs on a 5-point scale, ranging from 1 to 5 (very, some, middle, some, very). Each Big Five trait is represented by 7 items with clear factor structures (Tatar et al., 2019). In the present study, the BFI-35 Cronbach's $\alpha$ internal consistency score was .80 for extroversion, .68 for agreeableness, .83 for conscientiousness, .65 for emotional stability, and .82 for intellect.

State-Trait Anxiety Inventory (STAI). The StateTrait Anxiety Inventory, developed by Spielberger et al. (1970) and adapted for Turkish samples by Öner and Le Compte (1985), measures both trait and state anxiety levels. Each STAI subscale has 20 items in a 4-point Likert format, ranging from 1 (none) to 4 (entirely). In the present study, the Cronbach's $\alpha$ internal consistency scores were .90 for the state anxiety scale and .86 for trait anxiety scale.

COVID-19 Impact Questionnaire. This form, developed by the authors, asked background questions about age, gender, duration of competitive experience, league level, and marital status, and eight specific questions about COVID-19 experiences: 1) "How many times have you done field training with your coach in the past month?"; 2) "Does starting competitions soon make you nervous about being infected by coronavirus?" (yes or no options); 3) "Please mark your experience about the COVID-19 pandemic period" (options given with multiple responses allowed: "I got infected"; "My relatives got infected"; "My acquaintances got infected"; "Nobody I know got infected"; "I got tested for COVID-19"); 4) "How close do you think you may have been to any person infected with COVID-19?" (options given from 0 meters to 5 kilometers, and one for farther); 5) "How many people live in your household, including you?"; 6) "Did you experience a change in your relationship with your family or people close to you during the home confinement period?" (options given: "Positive change"; "Negative change"; "No change"); 7) "How worried are you or your family about being infected by the coronavirus?" (options given: "Extremely worried"; "Very worried"; "A little worried"; "Not worried"); 8) "Have you had difficulty spending your time at home during this period?" (yes or no options).

\section{STATISTICAL ANALYSES}

Multiple regression analyses were used to examine the variation in STAI scores in relation to BFI-35 scores. Before conducting the analyses, checks for autocorrelation between the predictor variables showed that no correlation coefficients were higher than .80. Pearson correlation scores ranged between .35 and .71. The Durbin-Watson (DW) scores for the first analysis (state anxiety) were 1.93 and 1.96 for trait anxiety. According to Field (2009), DW scores closer to 2 mean that the residuals of the model are uncorrelated. To avoid extreme values, Mahalanobis distance values were calculated for each case, which excluded 13 cases with residual values higher than 25 . Variance inflation factors (VIF) ranged between 1.01 and 3.17 while TOL scores ranged from .31 to .94 . These ranges were within the acceptable regression diagnostic values (Mason \& Perreault, 1991). All trait anxiety and state anxiety scores were all significantly (at the .001 level) negatively correlated with personality trait scores, ranging from -.29 to -.59 . Kerlinger (1973) recommends higher correlations between independent and dependent variables in regression analy- 
ses. The second statistical approach used ANOVA model statistics for grouping variables between personality traits. The ANOVA results are presented with the partial $\eta^{2}$ scores (Brown, 2008) representing the effect size. Scheffé post-hoc analyses were used to differentiate the subgroups' mean difference values. Levene's homogeneity of variance scores were also checked. When homogeneity was violated, Welch test scores were used instead of $F$ test results.

\section{RESULTS}

Regarding the general COVID-19 questionnaire, the participants reported the following experiences. Only 30 athletes (6.1\%) had been tested for COVID-19. Only 3 athletes reported being infected $(0.6 \%)$ while 17 family members had been infected (3.6\%) and 65 acquaintances (13.6\%). Most (393 athletes, 82.2\%) reported that nobody they knew had been infected. Thus, $17.8 \%$ of the athletes had either direct or indirect experience of COVID-19 infection.

The household sizes were distributed as follows: 1 person $15(3.1 \%), 2$ persons $50(10.2 \%), 3$ persons $101(20.6 \%), 4$ persons 189 (38.6\%), 5 persons $94(19.2 \%)$,
6 persons $26(5.3 \%), 7$ persons $11(2.2 \%), 8$ persons $2(0.4 \%), 9$ persons $1(0.2 \%)$. The participants gave the following estimations of how close they may have been to an infected person: 104 athletes $(21.3 \%)$ within 0-100 meters, 78 (15.9\%) within 500 meters, 87 (17.8\%) within 1 kilometer, 60 athletes $(12.5 \%)$ within 5 kilometers, 159 (32.5\%) over 5 kilometers. Thus, one in five athletes believe that an infected person may have been within 100 meters while one in three thinks that infected people could have been within 5 kilometers. If competitions were to restart soon, 297 athletes (60.7\%) were worried about COVID-19 whereas 192 athletes (39.3\%) were not.

Table 1 shows the means and standard deviations of the main variables broken down by gender. The mean age and years of competitive experience of female athletes were slightly higher than those of the male athletes. In addition, the mean trait anxiety and agreeableness scores of female athletes were higher than the men's.

The regression results for state anxiety, presented in Table 2, show that the model was significant at the .05 level. The predictor variables explained $28 \%$ of the variance in the athletes' state anxiety scores. Emotional stability and extroversion scores were strong

Table 1

Descriptive statistics of main variables by gender

\begin{tabular}{lccccc}
\hline & Gender & $N$ & Min & Max & M (SD) \\
\hline Age & Men & 321 & 15 & 39 & $20.60(5.60)$ \\
Competitive experience & Women & 168 & 15 & 34 & $22.60(4.79)$ \\
Een & 321 & 1 & 25 & $8.27(4.95)$ \\
Extroversion & Women & 168 & 1 & 28 & $10.57(5.64)$ \\
Agreeableness & Men & 321 & 8 & 35 & $26.00(4.87)$ \\
Comen & 168 & 10 & 35 & $26.57(5.21)$ \\
Emotional stability & Men & 321 & 9 & 35 & $26.74(4.19)$ \\
State anxiety & Women & 168 & 13 & 35 & $28.14(4.25)$ \\
Men & 321 & 7 & 35 & $28.02(4.84)$ \\
Intellect & Women & 168 & 8 & 35 & $28.95(4.95)$ \\
& Men & 321 & 9 & 35 & $23.37(4.37)$ \\
& Women & 168 & 8 & 33 & $23.05(4.37)$ \\
& Men & 321 & 7 & 35 & $29.11(4.21)$
\end{tabular}


The effect of Big Five traits on state and trait anxiety

Table 2

Regression analysis (dependent variable: state anxiety)

\begin{tabular}{lccc}
\hline State anxiety & $b$ & SE $b$ & $\beta$ \\
\hline Constant & 72.76 & 3.11 & \\
Extroversion & -.34 & .09 & $-.18^{* * *}$ \\
Agreeableness & -.14 & .12 & -.06 \\
Conscientiousness & -.16 & .11 & -.08 \\
Emotional stability & -.80 & .10 & $-.37^{* * *}$ \\
Intellect & .14 & .13 & .07 \\
Age & -.14 & .07 & $-.08^{*}$ \\
Gender & .42 & .80 & .02 \\
\hline Note. $R^{2}=.29 ; \Delta R^{2}=.28(p<.05) ;{ }^{*} p<.05,{ }^{* * *} p<.001$.
\end{tabular}

negative predictors of state anxiety. That is, athletes with high emotional stability and extroversion scores tended to have lower state anxiety scores. Age also significantly negatively predicted state anxiety. That is, older athletes tended to have lower state anxiety scores.

The regression analysis results for trait anxiety, presented in Table 3, show that this model was also significant at the .05 level. The predictor personality variables explained $43 \%$ of the variance in the athletes' trait anxiety scores. Emotional stability, extroversion, and conscientiousness all significantly negatively predicted trait anxiety, whereas agreeableness was a positive predictor. That is, athletes with high emotional stability, extroversion, and conscientiousness tended to have lower trait anxiety scores while athletes with high agreeableness tended to have higher trait anxiety scores. Gender also predicted trait anxiety at the .001 level.

Table 4 shows the ANOVA results for trait and state anxiety scores. Marital status had a significant effect on state anxiety. Single athletes had the highest state anxiety levels while married athletes had the lowest. Regarding their experiences of home confinement, athletes who perceived a negative change in their relationship with their close relatives had significantly higher trait and state anxiety levels than those reporting either no change or a positive change. In addition, athletes who reported difficulty staying at home reported significantly higher trait and state anxiety levels. Regarding fear of COVID-19, athletes who expressed greater fear had significantly higher trait anxiety levels than athletes in lower fear groups. However, the Scheffé post-hoc test did not discriminate any significance across the groups, so these ANOVA results were not confirmed. Regarding gender, women athletes' trait anxiety levels were significantly higher than men's, whereas there was no significant difference in state anxiety scores.
Table 3

Regression analysis (dependent variable: trait anxiety)

\begin{tabular}{lrrr}
\hline Trait anxiety & \multicolumn{1}{c}{$b$} & SE $b$ & $\beta$ \\
\hline Constant & 72.65 & 2.47 & \\
Extroversion & -.37 & .07 & $-.22^{* * *}$ \\
Agreeableness & .27 & .09 & $.14^{* *}$ \\
Conscientiousness & -.24 & .09 & $-.14^{* *}$ \\
Emotional stability & -.90 & .08 & $-.46^{* * *}$ \\
Intellect & -.14 & .10 & -.07 \\
Age & -.08 & .05 & -.05 \\
Gender & 2.30 & .63 & $.13^{* * *}$ \\
\hline Note. $R^{2}=.44 ; \Delta R^{2}=.43(p<.05){ }^{* *} p<.01,{ }^{* * *} p<.001$.
\end{tabular}

Regarding the pandemic's effects on relationships (Table 5), about half (54.8\%) of the athletes perceived no relationship change, $28 \%$ perceived a positive relationship change, and $17.2 \%$ perceived a negative change. The ANOVA results indicate that athletes reporting a negative relationship change had significantly lower agreeableness, conscientiousness, and emotional stability scores than athletes in the no change group and positive change groups at the .001 level. Scheffé post-hoc analyses revealed that agreeableness scores for the positive relationship change group were significantly higher than scores for the other two groups. The conscientiousness scores of the negative change group were significantly lower than those of the positive relationship change group. Athletes who perceived a negative change in their family relationship had significantly lower emotional stability scores than the other two groups. These results provide an opportunity to interpret how personality type affects personal relationships under extraordinary situations.

Difficulty in spending time at home during the COVID-19 pandemic was also significantly related to all five personality traits (Table 6). Athletes who perceived no difficulty staying at home had significantly higher extroversion, agreeableness, conscientiousness, emotional stability, and intellect scores than athletes who experienced difficulties.

\section{DISCUSSION}

This study showed that personality traits can affect athletes' anxiety levels and experiences during COVID-19 pandemic restrictions, while experiences and certain demographic characteristics can also increase anxiety. These results can help when creating programs for sports psychologists working with athletes during uncertain pandemic situations or similar challenging conditions. 
Gamze Üngür, Cengiz Karagözoğlu

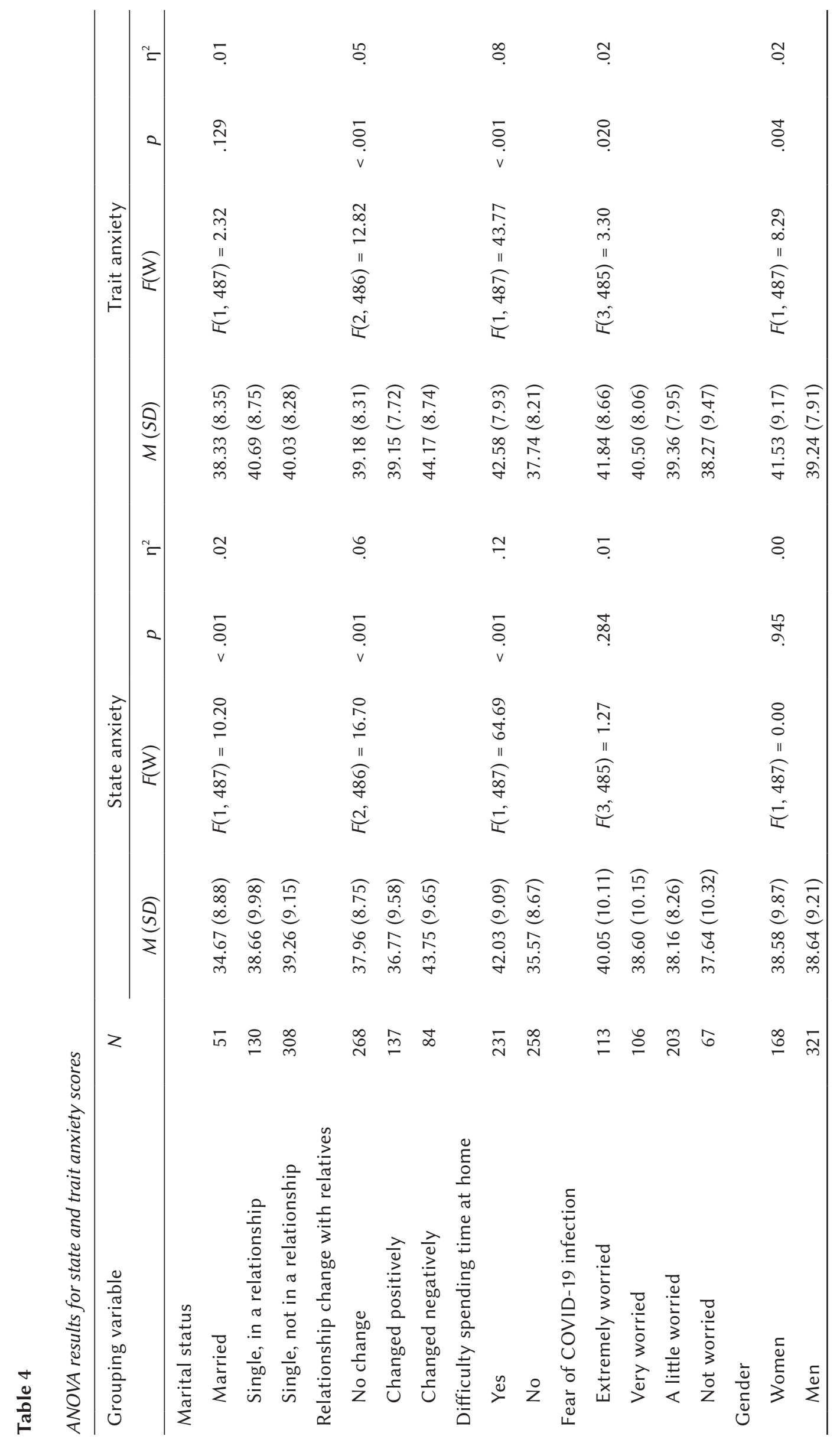


Table 5

ANOVA results of personality trait scores for athletes' perceived relationship change with relatives

\begin{tabular}{|c|c|c|c|c|c|c|}
\hline & $\begin{array}{c}\text { Relationship change } \\
\text { with relatives }\end{array}$ & $N$ & $M(S D)$ & $F(\mathrm{~W})$ & $p$ & $\eta^{2}$ \\
\hline \multirow[t]{3}{*}{ Extroversion } & No change & 268 & $26.17(4.98)$ & $F(2,486)=1.49$ & .225 & .01 \\
\hline & Changed positively & 137 & $26.70(4.86)$ & & & \\
\hline & Changed negatively & 84 & $25.51(5.22)$ & & & \\
\hline \multirow[t]{3}{*}{ Agreeableness } & No change & 268 & $27.00(4.20)$ & $F(2,486)=6.97$ & $<.001$ & .03 \\
\hline & Changed positively & 137 & $28.28(3.98)$ & & & \\
\hline & Changed negatively & 84 & $26.23(4.62)$ & & & \\
\hline \multirow[t]{3}{*}{ Conscientiousness } & No change & 268 & $28.41(4.76)$ & $F(2,486)=5.23$ & .006 & .02 \\
\hline & Changed positively & 137 & $29.09(4.55)$ & & & \\
\hline & Changed negatively & 84 & $26.92(5.56)$ & & & \\
\hline \multirow[t]{3}{*}{ Emotional stability } & No change & 268 & $23.68(4.29)$ & $F(2,486)=13.03$ & $<.001$ & .05 \\
\hline & Changed positively & 137 & $23.78(3.49)$ & & & \\
\hline & Changed negatively & 84 & $21.11(5.23)$ & & & \\
\hline \multirow[t]{3}{*}{ Intellect } & No change & 268 & $29.35(4.33)$ & $F(2,486)=0.42$ & .653 & .00 \\
\hline & Changed positively & 137 & $29.42(3.71)$ & & & \\
\hline & Changed negatively & 84 & $28.90(5.09)$ & & & \\
\hline
\end{tabular}

Table 6

ANOVA results of personality trait scores for perceived difficulty spending time at home

\begin{tabular}{lcccccc}
\hline & $\begin{array}{c}\text { Difficulty spending } \\
\text { time at home }\end{array}$ & $N$ & $M(S D)$ & $F(\mathrm{~W})$ & $p$ & $\eta^{2}$ \\
\hline Extroversion & Yes & 231 & $25.22(5.00)$ & $F(1,487)=17.72$ & $<.001$ & .04 \\
& No & 258 & $27.09(4.83)$ & & \\
Agreeableness & Yes & 231 & $26.29(4.44)$ & $F(1,487)=21.93$ & $<.001$ & .04 \\
Conscientiousness & No & 258 & $28.06(3.93)$ & & \\
& Yes & 231 & $27.12(5.36)$ & $F(1,487)=29.16$ & $<.001$ & .06 \\
Emotional Stability & No & 258 & $29.44(4.15)$ & & \\
Yntellect & Yes & 231 & $22.13(4.45)$ & $F(1,487)=31.29$ & $<.001$ & .06 \\
& No & 258 & $24.28(4.05)$ & & \\
\end{tabular}

In our study, both extraversion and emotional stability influenced athletes' state anxiety levels during home confinement, with introverted and neurotic athletes more likely to experience higher state anxiety. Similarly, Clemente-Suárez et al. (2020) found that neuroticism in Olympic athletes is associated with negative feelings about confinement whereas the ex- traversion trait is negatively associated with anxiety. Extraversion is often associated with positive emotions and energetic, pleasant, warm social behaviors (Costa \& McCrae, 1980; Laborde et al., 2019), whereas neuroticism is associated with unpleasant emotions such as anxiety, anger, or depression (Laborde et al., 2019). Extraversion can contribute to enjoying life or 
happiness even if unpleasant conditions cannot be changed, whereas neuroticism may increase an individual's suffering in the face of unfortunate situations (Costa \& McCrae, 1980). Furthermore, Nowakowska (2020) found that emotional stability and extroversion are significant predictors of low loneliness during the COVID-19 social distancing period. Thus, extraversion and emotional stability may help individuals overcome the COVID-19 home confinement phase, which is a very challenging period. Age also affected state anxiety in this study. Adolescents/ teenagers, who tend to feel emotions more intensely, may find it harder to be confined to their homes with parental attention during home confinement (Saho et al., 2020). This can create tensions that increase youngsters' state anxiety level.

In our study, low extroversion, conscientiousness, and emotional stability were all associated with higher trait anxiety. Karsten et al. (2012) also found that anxiety and depression disorders are associated with low conscientiousness and extraversion, and high neuroticism. Recovery from these disorders is associated with high conscientiousness and extraversion, and low neuroticism. Trait anxiety is often associated with neuroticism (Laborde et al., 2019), which is the opposite of emotional stability. That is, individuals with high emotional stability may have lower levels of trait anxiety. Traits that overlap with agreeableness and openness do not seem to be represented in sports and exercise psychology research as much as neuroticism and conscientiousness (Laborde et al., 2019). The unexpected effect of agreeableness on trait anxiety in the present study may reflect the legal limitations of the current extraordinary pandemic period. Indeed, Abdelrahman (2020) reported that individuals with high agreeableness show less compliance with social distancing rules during the COVID-19 pandemic as they generally wish to participate in social activities.

This study also shows that state and trait anxiety, and personality traits also affected participants' responses to questions regarding the COVID-19 pandemic period. Married athletes had lower state anxiety than single athletes, suggesting that it may be easier to share the difficulties of COVID-19 confinement when confined with a spouse. Being single is associated with higher stress in many domains, which in turn increases anxiety (Ta et al., 2017). Similarly, Sareshkeh and Bakhshalipour (2018) found that married athlete students had better mental health and social function than singles, and lower depression and fewer somatic symptoms Finally, Šljivo et al. (2020) recently reported that those who are older, single, female, or have moderate to severe depressive symptoms fear COVID-19 more.

In our study, state anxiety was higher in athletes whose relationships with their closest relatives were negatively affected during the pandemic. During highly stressful periods, social interaction through contacts with friends, neighbors, and various hobby groups, and perceived support can reduce state anxiety (Bolger \& Eckenrode, 1991). During the isolation period, athletes were unable to train or compete, or communicate in person with coaches and other athletes. Thus, they had insufficient activity and were isolated, which can harm the physical and mental state of athletes (Jukic et al., 2020). Since athletes were deprived of these connections, their anxiety levels were higher and their close relationships may have been damaged. An athlete with high trait anxiety may be more likely to experience negative effects in close relationships. Furthermore, given that athletes whose relationships were harmed during the lockdown have lower emotional stability, conscientiousness, and agreeableness, it implies that these traits may also affect close relationships. Related to this, Blagov (2020) found that conscientiousness and agreeableness are associated with more adaptive behaviors in obeying rules during the current pandemic whereas dark traits (e.g. psychopathy, meanness, disinhibition) are associated with lower compliance with healthy behaviors. Thus, these traits may also contribute to more harmonious relationships.

The postponements or cancellations of sports events and training have created many problems for athletes generally while they "are no longer able to follow their normal training schedules" (Lamberts \& Gomez-Ezeiza, 2020). One of the most important issues facing athletes during home confinement, who are very active in their normal life, is finding ways to pass their time. As the present study showed, athletes who reported difficulty spending time at home had higher state anxiety levels. Thus, it is critical to plan the time spent at home effectively. As Ustun (2020) showed, individuals who spend time with their families during the COVID-19 pandemic and are busy with educational or work programs have lower depression scores. It should also be noted that the athletes who reported difficulty spending time at home also have high trait anxiety, which may indicate that high trait anxiety makes people less able to cope with such challenging conditions.

Regarding Big Five personality traits, the athletes in our study who reported difficulty spending time at home had lower scores in all traits (extroversion, agreeableness, conscientiousness, emotional stability, and intellect), which indicates that personality may also affect the quality of time spent at home. Although sports psychologists working with Olympic candidates during the pandemic period have offered a wide variety of suggestions, they emphasize the importance of open communication about the athletes' thoughts and feelings (Schinke et al., 2020). Within this open communication environment, they recommend that consultants consider the athletes' personality traits to determine more clearly what they are 
experiencing so as to choose the appropriate intervention methods.

Some athletes can develop strategies to deal with months of confinement, whereas others cannot cope, resulting in increased anxiety and stress that can devastate their daily lives (Pakpour \& Griffiths, 2020). Predictably, those athletes who reported being extremely afraid of COVID-19 infection for themselves or their relatives had high trait anxiety. Similarly, Ustun (2020) found that people who are afraid of COVID-19 infection and infecting others also report obsessive cleanliness, future anxiety, and sadness, which in turn are associated with midlevel depression symptoms. Most of the athletes participating in the study believed that there were infected people in their neighborhood even if they did not know of anyone who had been infected around them. They were also concerned about infection if competitions started soon. These findings highlight the importance of managing anxiety levels and for consultants to provide psychological support to athletes during this period.

Regarding gender, the pandemic period seems likely to have had a greater psychological impact on women than men, as the women athletes in this study had higher trait anxiety, as also reported with college swimmers (Tobar, 2012). Women in Turkey also had higher anxiety and depression during the COVID-19 pandemic (Özdin \& Bayrak Özdin, 2020). Similarly, di Fronso et al. (2020) found higher perceived stress in female athletes during the COVID-19 pandemic. Pons et al. (2020) reported that the COVID-19 lockdown had negatively affected athletes in general, but female athletes more. However, we should also note that female athletes may use different coping strategies (Nicholls \& Polman, 2007) despite their high levels of anxiety.

The mean STAI scores in the current study are somewhat higher than those from other anxiety studies conducted with athletes before the COVID-19 pandemic. For example, Küçük and Erbaş (2012) reported a mean state anxiety score of 30.46 for elite male basketball players in Turkey; Ivaskevych et al. (2020) reported a score of 36.00 for Ukrainian national woman handball players; Kaplan et al. (2008) reported state anxiety scores for university futsal players of 30.86 before and 25.82 after a tournament. In contrast, Çağlar (1999) reported a mean state anxiety score of 38.29 for Turkish elite male junior handball players five days before a competition, which is closer to our findings during the COVID-19 pandemic of 38.64 in men and 38.58 in women athletes.

\section{CONCLUSIONS}

The current study's findings have implications for psychological assessment and interventions with athletes during the COVID-19 pandemic. More spe- cifically, their personality plays an important role in the effects of the COVID-19 period when sporting events were mostly postponed or cancelled. High emotional stability, extraversion, and conscientiousness help reduce anxiety during the pandemic while high agreeableness, conscientiousness, and emotional stability may help athletes maintain positive relationships.

With its global consequences, the COVID-19 pandemic has affected athletes and the sports community as well, increasing the importance of providing psychological support for athletes during and after this uncertain period. Athletes may be affected in various ways depending on their individual differences. The study's results indicate that the personality traits should be considered when preparing programs for athletes. In addition, marital status and close relationships play an important role in dealing with this period. Thus, considering such issues related to the athletes' private lives can help practitioners determine appropriate intervention methods. Furthermore, personality traits can be examined in terms of their effects on specific variables. Following the break due to the COVID-19 pandemic, some sports have restarted competitions. We recommend conducting studies on the experiences, mental state, and performance of these athletes.

\section{RefERENCES}

Abdelrahman, M. (2020). Personality traits, risk perception, and protective behaviors of Arab residents of Qatar during the COVID-19 pandemic. International Journal of Mental Health and Addiction. https://doi.org/10.1007/s11469-020-00352-7

Aşkın, R., Bozkurt, Y., \& Zeybek, Z. (2020). COVID-19 pandemic: Psychological therapeutic interventions. Istanbul Ticaret University Journal of Social Sciences, 19, 304-318.

Bacon, A. M., \& Corr, P. J. (2020). Coronavirus (COVID-19) in the United Kingdom: a personality-based perspective on concerns and intention to self-isolate. British Journal of Health Psychology, 25, 839-848. https://doi.org/10.1111/bjhp. 12423

Blagov, P. (2020). Adaptive and dark personality traits in the COVID-19 pandemic: Predicting health-behavior endorsement and the appeal of public-health messages. Social Psychological and Personality Science. https://doi.org/10.1177/1948550620936439

Blocken, B., van Druenen, T., van Hooff, T., Verstappen, P. A., Marchal, T., \& Marr, L. C. (2020). Can indoor sports centers be allowed to re-open during the COVID-19 pandemic based on a certificate of equivalence? Building and Environment, 180, 107022. https://doi.org/10.1016/j.buildenv.2020.107022

Bolger, N., \& Eckenrode, J. (1991). Social relationships, personality, and anxiety during a major stressful 
event. Journal of Personality and Social Psychology, 61, 440-449. https://doi.org/10.1037/0022-3514. 61.3.440

Brouard, S., Vasilopoulos, P., \& Becher, M. (2020). Sociodemographic and psychological correlates of compliance with the COVID-19 public health measures in France. Canadian Journal of Political Science, 53, 253-258. https://doi.org/10.1017/S00084 23920000335

Brown, J. D. (2008). Effect size and eta squared. Shiken: JALT Testing \& Evaluation SIG Newsletter, 12, 38-43.

Çağlar, E. (1999). Temporal changes of anxiety levels of the youth and junior male handball national team players. Hacettepe Journal of Sport Sciences, 3, 19-28.

Carmody, S., Murray, A., Borodina, M., Gouttebarge, V., \& Massey, A. (2020). When can professional sport recommence safely during the COVID-19 pandemic? Risk assessment and factors to consider. British Journal of Sports Medicine, 54, 946-948. https://doi.org/10.1136/bjsports-2020102539

Carvalho, L. F., Pianowski, G., \& Gonçalves, A. P. (2020). Personality differences and COVID-19: Are extroversion and conscientiousness personality traits associated with engagement with containment measures? Trends in Psychiatry and Psychotherapy, 42, 179-184. https://doi.org/10.1590/22376089-2020-0029

Claussen, M. C., \& Scherr, J. (2020). Fact sheet: Sport psychiatric and psychotherapeutic aspects in competitive sports in times of the COVID 19 pandemic. Deutsche Zeitschrift Fur Sportmedizin, 71, E1-E2. https://doi.org/10.5960/dzsm.2020.436

Clemente-Suárez, V. J., Fuentes-García, J. P., de la Vega Marcos, R., \& Martínez Patiño, M. J. (2020). Modulators of the personal and professional threat perception of Olympic athletes in the actual COVID-19 crisis. Frontiers in Psychology, 11, 1985. https://doi.org/10.3389/fpsyg.2020.01985

Corsini, A., Bisciotti, G. N., Eirale, C., \& Volpi, P. (2020). Football cannot restart soon during the COVID-19 emergency! A critical perspective from the Italian experience and a call for action. British Journal of Sports Medicine, 54, 1186-1187. https:// doi.org/10.1136/bjsports-2020-102306

Costa, P. T., \& McCrae, R. R. (1980). Influence of extraversion and neuroticism on subjective wellbeing: Happy and unhappy people. Journal of Personality and Social Psychology, 38, 668-678. https://doi.org/10.1037/0022-3514.38.4.668

De Moor, M. H. M., Beem, A. L., Stubbe, J. H., Boomsma, D. I., \& De Geus, E. J. C. (2006). Regular exercise, anxiety, depression and personality: a population-based study. Preventive Medicine, 42, 273-279. https://doi.org/10.1016/j.ypmed.2005.12.002

di Fronso, S., Costa, S., Montesano, C., Di Gruttola, F., Ciofi, E. G., Morgilli, L., Robazza, C., \& Ber- tollo, M. (2020). The effects of COVID-19 pandemic on perceived stress and psychobiosocial states in Italian athletes. International Journal of Sport and Exercise Psychology. https://doi.org/10.1080/1 612197X.2020.1802612

Field, A. (2009). Discovering statistics using SPSS (Third edition). Sage Publications.

Garbe, L., Rau, R., \& Toppe, T. (2020). Influence of perceived threat of COVID-19 and HEXACO personality traits on toilet paper stockpiling. PloS One, 15, e0234232. https://doi.org/10.1371/journal. pone. 0234232

Goldberg, L. R. (1992). The development of markers for big five factor structure. Psychological Assessment, 4, 26-42. http://dx.doi.org/10.1037/1040-3590.4.1.26

Ivaskevych, D., Fedorchuk, S., Petrushevskyi, Y., Borysova, O., Ivaskevych, O., Kohut, I., Marynych, V., \& Tukaiev, S. (2020). Association between competitive anxiety, hardiness, and coping strategies: a study of the national handball team. Journal of Physical Education and Sport, 20, 359-365. https:// doi.org/10.7752/jpes.2020.s1051

Jukic, I., Calleja-González, J., Cos, F., Cuzzolin, F., Olmo, J., Terrados, N., Njaradi, N., Sassi, R., Requena, B., Milanovic, L., Krakan, I., Chatzichristos, K., \& Alcaraz, P. E. (2020). Strategies and solutions for team sports athletes in isolation due to COVID-19. Sports, 8, 56. https://doi.org/10.3390/sports8040056 Kaplan, T., Taşkın, H., Altın, M., \& Erkmen, N. (2008). Examination of the level of state anxiety points of the soccer players during the tournament. Selcuk University Journal of Social Sciences Institute, 20, 447-456.

Karsten, J., Penninx, B. W. J. H., Riese, H., Ormel, J., Nolen, W. A., \& Hartman, C. A. (2012). The state effect of depressive and anxiety disorders on big five personality traits. Journal of Psychiatric Research, 46, 644-650. https://doi.org/10.1016/j.jpsychires.2012.01.024

Kerlinger, F. N. (1973). Foundations of Behavioral Research. Holt-Saunders International Editions.

Küçük, V., \& Erbaş, M. K. (2012). Comparisons of the state anxiety level according to the different variables in top level basketball players. Selçuk University Journal of Physical Education and Sport Science, 14, 257-261.

Laborde, S., Allen, M. S., Katschak, K., Mattonet, K., \& Lachner, N. (2019). Trait personality in sport and exercise psychology: a mapping review and research agenda. International Journal of Sport and Exercise Psychology, 18, 701-716. https://doi.org/ 10.1080/1612197x.2019.1570536

Lamberts, R., \& Gomez-Ezeiza, J. (2020). The confinement of athletes by COVID-19: Effects on training, wellbeing and the challenges when returning to competition. European Journal of Human Movement, 44,1-4.https://doi.org/10.21134/eurjhm.2020. 44.559 
Leandro, P. G., \& Castillo, M. D. (2010). Coping with stress and its relationship with personality dimensions, anxiety, and depression. Procedia - Social and Behavioral Sciences, 5, 1562-1573. https:// doi.org/10.1016/j.sbspro.2010.07.326

Mann, R. H., Clift, B. C., Boykoff, J., \& Bekker, S. (2020). Athletes as community; athletes in community: COVID-19, sporting mega-events and athlete health protection. British Journal of Sports Medicine, 54, 1071-1072. https://doi.org/10.1136/ bjsports-2020-102433

Mason, C. H., \& Perreault, W. D. (1991). Collinearity, power, and interpretation of multiple regression analysis. Journal of Marketing Research, 28, 268280. https://doi.org/10.1177/002224379102800302

Nicholls, A. R., \& Polman, R. C. J. (2007). Coping in sport: a systematic review. Journal of Sports Sciences, 25, 11-31. https://doi.org/10.1080/02640410600630654

Nowakowska, I. (2020). Lonely and thinking about the past: The role of time perspectives, Big Five traits and perceived social support in loneliness of young adults during COVID-19 social distancing. Current Issues in Personality Psychology, 8, 175-184. https://doi.org/10.5114/cipp.2020.97289

Öner, N., \& Le Compte, A. (1985). Handbook of StateTrait Anxiety Inventory. Bogazici University Publication.

Özdin, S., \& Bayrak Özdin, Ş. (2020). Levels and predictors of anxiety, depression and health anxiety during COVID-19 pandemic in Turkish society: The importance of gender. International Journal of Social Psychiatry, 66, 504-511. https://doi.org/ 10.1177/0020764020927051

Pakpour, A. H., \& Griffiths, M. D. (2020). The fear of COVID-19 and its role in preventive behaviors. Journal of Concurrent Disorders, 2, 58-63. https:// doi.org/10.1017/CBO9781107415324.004

Paoli, A., \& Musumeci, G. (2020). Elite athletes and COVID-19 lockdown: Future health concerns for an entire sector. Journal of Functional Morphology and Kinesiology, 5, 10-12. https://doi.org/10.3390/ jfmk5020030

Pillay, L., Janse van Rensburg, D. C. C., Jansen van Rensburg, A., Ramagole, D. A., Holtzhausen, L., Dijkstra, H. P., \& Cronje, T. (2020). Nowhere to hide: The significant impact of coronavirus disease 2019 (COVID-19) measures on elite and semi-elite South African athletes. Journal of Science and Medicine in Sport, 23, 670-679. https://doi.org/10.1016/j. jsams.2020.05.016

Pons, J., Ramis, Y., Alcaraz, S., Jordana, A., Borrueco, M., \& Torregrossa, M. (2020). Where did all the sport go? Negative impact of COVID-19 lockdown on life-spheres and mental health of Spanish young athletes. Frontiers in Psychology, 11, 611872. https://doi.org/10.3389/fpsyg.2020.611872

Saho, S., Rani, S., Shah, R., Singh, A. P., Mehra, A., \& Grover, S. (2020). COVID-19 pandemic-related anxiety in teenagers. Indian Journal of Psychiatry, 62, 328-330. https://doi.org/10.4103/psychiatry.IndianJPsychiatry_327_20

Salari, N., Hosseinian-Far, A., Jalali, R., Vaisi-Raygani, A., Rasoulpoor, S., Mohammadi, M., Rasoulpoor, S., \& Khaledi-Paveh, B. (2020). Prevalence of stress, anxiety, depression among the general population during the COVID-19 pandemic: a systematic review and meta-analysis. Globalization and Health, 16, 57. https://doi.org/10.1186/s12992020-00589-w

Sareshkeh, S. K., \& Bakhshalipour V. (2018). The effect of exercise on athlete and non-athlete students' mental health in physical dimension, anxiety, sleep disturbance, social function, and depression. The Russian Journal of Physical Education and Sport, 13, 107-114. https://doi.org/10.14526/02_2018_317

Schinke, R., Papaioannou, A., Henriksen, K., Si, G., Zhang, L., \& Haberl, P. (2020). Sport psychology services to high performance athletes during COVID-19. International Journal of Sport and Exercise Psychology, 18, 269-272. https://doi.org/10.108 0/1612197X.2020.1754616

Šljivo, A., Kaamakovi, M., Quraishi, I., \& Kulenovi, A. D. (2020). Fear and depression among residents of Bosnia and Herzegovina during COVID-19 outbreak - Internet survey. Psychiatria Danubina, 32, 266-272. https://doi.org/10.24869/PSYD.2020.266 Spielberger, C. D., Gorsuch, R. L., \& Lushene, R. E. (1970). State-Trait Anxiety Inventory for adults (Form X). Consulting Psychologists Press.

Stokes, K. A., Jones, B., Bennett, M., Close, G. L., Gill, N., Hull, J. H., Kasper, A. M., Kemp, S. P. T., Mellalieu, S. D., Peirce, N., Stewart, B., Wall, B. T., West, S. W., \& Cross, M. (2020). Returning to play after prolonged training restrictions in professional collision sports. International Journal of Sports Medicine, 41, 895-911. https://doi.org/10. 1055/a-1180-3692

Ta, V. P., Gesselman, A. N., Perry, B. L., Fisher, H. E., \& Garcia, J. R. (2017). Stress of singlehood: Marital status, domain-specific stress, and anxiety in a national U.S. sample. Journal of Social and Clinical Psychology, 36, 461-485. https://doi.org/10.1521/ jscp.2017.36.6.461

Taku, K., \& Arai, H. (2020). Impact of COVID-19 on athletes and coaches, and their values in Japan: Repercussions of postponing the Tokyo 2020 Olympic and Paralympic Games. Journal of Loss and Trauma, 25, 623-630. https://doi.org/10.1080/ 15325024.2020.1777762

Tatar, A., Çelikbaş, B., \& Özdemir, H. (2019). Examining psychometric characteristics of The Big Five Inventory-35 Turkish form. Journal of Social, $\mathrm{Hu}$ manities and Administrative Sciences, 5, 300-309. https://doi.org/10.31589/JOSHAS.114

Tekkurşun Demir, G., Cicioğlu, H. İ., \& İlhan, E. L. (2020). Anxiety of Catching the Novel Coronavi- 
rus (COVID-19) Scale (ACNCS): Validity and reliability study. Journal of Human Sciences, 17, 458468. https://doi.org/10.14687/jhs.v17i2.5988

Tobar, D. A. (2012). Trait anxiety and mood state responses to overtraining in men and women college swimmers. International Journal of Sport and Exercise Psychology, 10, 135-148. https://doi.org/ 10.1080/1612197X.2012.666399

Toresdahl, B. G., \& Asif, I. M. (2020). Coronavirus disease 2019 (COVID-19): Considerations for the competitive athlete. Sports Health, 12, 221-224. https://doi.org/10.1177/1941738120918876

Ustun, G. (2020). Determining depression and related factors in a society affected by COVID-19 pandemic. The International Journal of Social Psychiatry. https://doi.org/10.1177/0020764020938807 